\title{
A Different Kind of Microscopy: Analyzing Features with an Automated Electron Beam
}

\author{
Frederick H. Schamber*, and Cornelis (Kai) G. van Beek* \\ *Aspex Corporation, 175 Sheffield Drive, Delmont, PA 15626
}

Scanning electron microscopes equipped with energy dispersive x-ray spectrometers have been commercially computer-automated since the 1970s. Such automated analysis capability has generally been regarded as an extension of the basic SEM/EDX instrument but this perception is changing as more applications emerge where the automated mode is the primary (and frequently the sole) mode of operation. One traditional application of this type is the automated detection of gunshot residue particles in criminal forensics. Other applications apply the technology to assessment of critical cleanliness in equipment manufacturing, quality control in pharmaceutical production, and predictive maintenance of jet aircraft engines and other high-value mechanisms. As the unique capabilities of the technique are more widely recognized and applied, there is a growing appreciation that this kind of automated analysis is not just another application of SEM/EDX, but constitutes a different kind of microscopy.

Applications of the type listed above make use of familiar SEM/EDX functionality to perform their tasks, but both the motivation and the optimal implementation are substantially different from those that pertain to manually operated SEM/EDX installations. These differences begin with the role of the human operator. A conventional SEM functions as a sensory extension of its operator and performs no useful function without someone seated at the controls. In an automated application, the goal is not only to produce useful results unattended, but also to produce data much faster and more consistently than any human could. Whereas "a good days work" for a manual SEM might be the thorough assessment of a single critical feature, documented with high quality micrographs, $\mathrm{x}$ ray spectra, and compositional maps, a days work for an automated feature analyzer could easily be the analysis of 100,000 discrete features, classified into relevant categories according to size, shape, and composition. The manual analysis produces depth of information regarding individual features; automated analysis is intended to produce statistically meaningful information about populations of features. Other significant differences are listed in Table 1.

Given the differences in objectives between a manually operated SEM/EDX installation and an automated one, it is not surprising that the configuration of an optimal instrument is also different. One key difference is in the way the focused electron beam is most productively employed. The image is the center of attention for all conventional SEMs, yet we sometimes forget that the SEM image is assembled from a series of point-wise measurements. An optimized feature analysis instrument can optimize speed and precision by utilizing the electron beam as a dynamic probe to directly detect and measure features without collecting complete image frames. The instrument can thus directly extract numeric measures of the features of interest without the overhead of collecting full frames of largely irrelevant information (although images of features can also be automatically captured as supplementary information).

With the increased use of automated feature analyzers in regulated environments, there is increasing importance placed on verifying the instrument's performance. In a manual installation, this is the 
implicit responsibility of the operator, but automated instruments can't make this assumption. As a consequence, increased attention is being paid to making these instruments self-checking and selfcalibrating. Recent development of a novel system for rapid and detailed performance checking (patents pending), based on a specially fabricated specimen and an accompanying software component, now offers a practical way that this can be routinely accomplished. For quality control applications it is imperative that the sensitivity of the instrument be understood in detail, and because this is a statistical process, it is not acceptable to extrapolate from a few measurements. The new system provides the means whereby thousands of well-characterized features of varying sizes, shapes, composition, and contrast can be rapidly assessed, and detailed performance metrics extracted. Not only does this system provide a practical means for routine instrument capability checks by users, but it is also proving to be a uniquely powerful tool for further refining the design of the instrument.

In summary: Automated feature analysis instruments are employed in ways that are fundamentally different from their manual-SEM cousins, and their optimal configuration reflects these differences. The process of evolutionary optimization, already evident in the instruments of today, can be expected to continue in the future.

Table 1: Differences between Conventional Manual SEM and Automated Feature Analyzer

\begin{tabular}{|l|l|}
\hline \multicolumn{2}{|c|}{ Conventional Manual SEM Differences in Objectives } \\
\hline \multicolumn{2}{|c|}{ Automated Feature Analyzer } \\
\hline $\begin{array}{l}\text { Visual images are primary output } \\
\text { measure of performance }\end{array}$ & Tabulated numeric data is primary output \\
\hline Frequent idle time is normal & $\begin{array}{l}\text { Independence from operator subjectivity is } \\
\text { important goal }\end{array}$ \\
\hline $\begin{array}{l}\text { Supports operator skilled in microscope } \\
\text { operation and data interpretation }\end{array}$ & $\begin{array}{l}\text { Instrument may operate 24/7/365 } \\
\text { instrument to collect reliable data }\end{array}$ \\
\hline Limited output of highest possible quality & Maximum output of appropriate quality \\
\hline Generality and flexibility are important & Efficiency for dedicated application is the goal \\
\hline \multicolumn{2}{|c|}{ Dimal Implementation } \\
\hline $\begin{array}{l}\text { Contiguous high-density arrays of pixels are } \\
\text { captured and presented for inspection }\end{array}$ & $\begin{array}{l}\text { Electron beam is moved dynamically to locate } \\
\text { and selectively characterize individual features }\end{array}$ \\
\hline $\begin{array}{l}\text { Specimen stage is designed for convenient } \\
\text { manipulation while viewing - often manual }\end{array}$ & $\begin{array}{l}\text { Stage is optimized for fast, precise movement } \\
\text { between fields of view - must be motorized }\end{array}$ \\
\hline $\begin{array}{l}\text { Small stage capacity an acceptable } \\
\text { compromise for rigidity during high- } \\
\text { resolution imaging }\end{array}$ & $\begin{array}{l}\text { Large stage motion required for handling of large } \\
\text { and/or multiple specimens }\end{array}$ \\
\hline $\begin{array}{l}\text { Secondary electron detector is standard for } \\
\text { high resolution topographic imaging }\end{array}$ & $\begin{array}{l}\text { Backscatter electron detector is standard for } \\
\text { reliably distinguishing features }\end{array}$ \\
\hline $\begin{array}{l}\text { Energy resolution of EDX is important for } \\
\text { visual spectrum interpretation }\end{array}$ & $\begin{array}{l}\text { Throughput and stability of EDX are important } \\
\text { for rapid precise algorithmic interpretation }\end{array}$ \\
\hline $\begin{array}{l}\text { Electron optics designed to achieve best } \\
\text { resolution specification }\end{array}$ & $\begin{array}{l}\text { Electron optics optimized for stability and simple } \\
\text { maintenance }\end{array}$ \\
\hline Comfortable operation for a seated operator & Walk-up setup and remote status checking \\
\hline Hardcopy output is essential & Output may go directly into database \\
\hline No data security & Rigorous data security often required \\
\hline
\end{tabular}

